\title{
Systemic decision making in AHP: a Bayesian approach
}

\author{
José María Moreno-Jiménez • Manuel Salvador • \\ Pilar Gargallo • Alfredo Altuzarra
}

(C) Springer Science+Business Media New York 2014

\begin{abstract}
Systemic decision making is a new approach for dealing with complex multiactor decision making problems in which the actors' individual preferences on a fixed set of alternatives are incorporated in a holistic view in accordance with the "principle of tolerance". The new approach integrates all the preferences, even if they are encapsulated in differ5 ent individual theoretical models or approaches; the only requirement is that they must be 6 expressed as some kind of probability distribution. In this paper, assuming the analytic hier7 archy process (AHP) is the multicriteria technique employed to rank alternatives, the authors present a new methodology based on a Bayesian analysis for dealing with AHP systemic decision making in a local context (a single criterion). The approach integrates the individual visions of reality into a collective one by means of a tolerance distribution, which is defined as the weighted geometric mean of the individual preferences expressed as probability distributions. A mathematical justification of this distribution, a study of its statistical properties and a Monte Carlo method for drawing samples are also provided. The paper further presents a number of decisional tools for the evaluation of the acceptance of the tolerance distribution, the construction of tolerance paths that increase representativeness and the extraction of the relevant knowledge of the subjacent multiactor decisional process from a cognitive perspective. Finally, the proposed methodology is applied to the AHP-multiplicative model with lognormal errors and a case study related to a real-life experience in local participatory budgets for the Zaragoza City Council (Spain).
\end{abstract}

Keywords Multiactor decision making - Systemic decision making - Tolerance distribution $\cdot$ AHP $\cdot$ Bayesian inference $\cdot$ Participatory budgets

J. M. Moreno-Jiménez $(\varangle) \cdot$ M. Salvador · P. Gargallo · A. Altuzarra

Grupo Decisión Multicriterio Zaragoza, Facultad de Economía y Empresa, Universidad de Zaragoza, 50005 Zaragoza, Spain

e-mail: moreno@unizar.es 


\section{Introduction}

Some of the most significant characteristics of the knowledge society (KS) are: the participation and interdependencies of multiple actors; the consideration of intangible, subjective and emotional aspects; the interrelation between determinants; and the holistic vision of reality that is considered in decision making processes. This new societal context requires scientific approaches which provide an appropriate response to new needs and requirements, in particular, those needs associated with the key component of the Knowledge Society: the human factor in multiactor settings.

Moreno-Jiménez (2003a) and Escobar and Moreno-Jiménez (2007) identified three multiple actor decision making situations: (1) group decision making (GDM), (2) negotiated decision making (NDM); and (3) systemic decision making (SDM).

In the first situation (GDM), individuals work together in pursuit of a common goal under the principle of consensus. Consensus refers to the approach, model, tools, and procedures for deriving the final group priority vector. In the second situation (NDM), assuming that all the actors follow the same scientific approach, each individual resolves the problem separately, the zones of agreement and disagreement between the actors are identified and agreement paths (sometimes known as consensus paths) are constructed by changing one or several judgements. In the third situation (SDM), in accordance with the principle of tolerance, each individual acts independently and the individual preferences, expressed as probability distributions, are aggregated to form a collective one, denominated as the tolerance distribution. This new approach integrates all the preferences, even if they are encapsulated in different "individual theoretical models"; the only requirement is that they must be expressed as some kind of probability distribution. This means that the systemic situation for dealing with multiactor decision making allows the capturing of the holistic vision of reality and the subjacent ideas of lateral thinking (Bono 1970). The information provided by the tolerance distribution can be used to construct tolerance paths to gain a more democratic and representative final decision, that is to say, a decision will be accepted, by a greater number of actors or by a number of actors with greater weighting in the decisional process.

Due to its flexibility and adaptability in complex decision making contexts, one of the most widely used techniques in decisional processes involving multiple actors, scenarios and criteria is Saaty's analytic hierarchy process (AHP) (Saaty 1972, 1980). AHP contemplates the philosophical changes (from mechanistic reductionism to evolutionist holism), methodological changes (from the search for truth to the search for knowledge) and technological changes (from information communication to knowledge generation and diffusion) that have been taking place since the end of the twentieth century (Moreno-Jiménez 2003a; Altuzarra et al. 2007).

AHP methodology constructs an absolute scale associated with the priorities of the elements being compared. There are four steps: (1) Modelling - the decision making problem as a hierarchy in which criteria, subcriteria (several levels if necessary), attributes and alternatives are incorporated; (2) Valuation - the incorporation into the hierarchy of the individual preferences by means of the judgements elicited to fill the pairwise comparison matrices. The judgements belong to Saaty's fundamental scale (Saaty 1980); (3) Prioritisation of the elements of the hierarchy using any of the existing prioritisation procedures (local priorities) and the hierarchical composition principle (global priorities); (4) Synthesis of the global priorities of the alternatives to obtain their total or final priorities using an aggregation procedure. In contrast to other multicriteria techniques, AHP allows an assessment of inconsistency in the judgement elicitation process. Two of the most widely used procedures in the AHP literature are Saaty's Consistency Ratio (Saaty 1980) and the Geometric Consistency Index (Aguarón 
and Moreno-Jiménez 2003), used with the Eigenvector Prioritization Method (EGVM) and the Row Geometric Mean Method (RGMM), respectively.

With AHP-Group Decision Making (AHP-GDM), the two procedures conventio employed to obtain the group priorities in a determinist context (Saaty 1980; Ramanathan Ganesh 1994; Forman and Peniwati 1998) are: (1) the Aggregation of Individual Judgements (AIJ) and (2) the Aggregation of Individual Priorities (AIP). The first is used when the group works as a synergistic unit and the second when the group functions as a collective of individuals (Forman and Peniwati 1998). These traditional (deterministic) approaches and some more recent proposals for the stochastic context have been discussed in the literature:

Altuzarra et al. (2007) presented a more efficient Bayesian prioritisation procedure for AHP-GDM, than (the commonly employed) AIJ and AIP; Escobar and Moreno-Jiménez (2007) developed the Aggregation of Individual Preference Structures (AIPS) which captures the vision and uncertainty of decision makers and the contextual interdependences of the alternatives. AHP-GDM approaches include: Goal Programming (Bryson 1996; Bryson and Jones 9 ); Interval Judgements (Hämäläinen and Pöyhönen 1996); Stochastic Preference Modelling (Honert 1998); Fuzzy Preference Programming (Mikhailov 2004); Taguchi's Loss Function (Cho and Cho 2008); Nonlinear Least Squares Regression (Lipovetsky 2009); Linear Programming (Hosseinian et al. 2012); and the Dong et al. (2010) idea for two new AHP consensus models that improve original inconsistency and satisfy the Pareto Principle of Social Choice. A comparison of different AHP-GDM methods can be seen in Peniwati (2007), Saaty and Peniwati (2008) and Huang et al. (2009).

Using the property of consistency, Moreno-Jiménez et al. $(2005,2008)$ advanced a consensus searching decisional tool, the Consistent Consensus Matrix (CCM), which has been recently extended (Precise Consistent Consensus Matrix) in order to increase the number of entries considered in the CCM and the accuracy of the estimations (Aguarón et al. 2014).

There are also a number of approaches to AHP Negotiated Decision Making (AHPNDM): Gargallo et al. (2007) put forward a Bayesian procedure based on the use of mixtures in cases with a large number of actors where a prior consensus is not required. They further developed graphic tools and clustering algorithms to identify homogeneous groups of actors with different patterns of behaviours for the priority rankings; Altuzarra et al. (2010), working in a local context and with a small number of actors, introduced a semi-automatic procedure for the search for consensus that works with complete and incomplete matrices. They use a hierarchical Bayesian regression linear model with log-normal errors and Monte Carlo Markov Chain (MCMC) methods to estimate the agreement priorities. In the same paper, these authors also advocate criteria for measuring the degree of agreement or compatibility between individual and collective priority vectors and use optimisation procedures based on genetic algorithms for developing consensus paths among the actors.

In the context of AHP-NDM: Honert and Lootsma (2000) developed the relative strength of the negotiating position of each of the bargaining parties; Hämäläinen's (2003) Decisionarium (http://www.decisionarium.hut.fi) is a public site for interactive multicriteria decision support with tools for individual decision making and group collaboration and negotiation; Bellucci and Zeleznikow (2005) Negotiation Decision Support Systems is based on the use of tradeoff manipulations; Chen and Huang (2007) published a scheme aimed at the uncertainty and imprecision of identifying suitable supplier offers, evaluating the offers and choosing the best alternatives in bi-negotiation; and Altuzarra et al. (2013) have recently compiled a taxonomy for criteria, taking into account their influence and relevance in the final ranking of the alternatives.

In this paper, the authors consider the third and most original situation in the AHP context AHP systemic decision making (AHP-SDM). The situation assumes that the actors indepen- 
dently elicit their judgements and the individual preferences within a fixed set of alternatives are given a type of probability distribution that reflects the intensity of the preferences. Once the actors' individual preferences are established, they look for a holistic decision, based on the principle of tolerance which attempts to link multiactor decision making with one of the main ideas of lateral thinking (Bono 1970): the parallel integration of the visions of reality of all the actors involved in the resolution process. This systemic decision making context is addressed by a Bayesian procedure similar to that which is considered by Altuzarra et al. (2007, 2010).

With the aim of reaching a joint position for the group, the first step is to define a tolerance distribution as the weighted geometric mean of the individual priorities distribution. The tolerance distribution allows the integration of the actors' vision of reality by minimising a weighted average of the Kullback-Leibler distances between it and each decision maker's individual priorities distribution. The statistical properties of this distribution are also examined and as it is not usually analytically tractable, the authors have designed an algorithm to draw samples, that will be used (from a cognitive perspective - Moreno-Jiménez et al. 2001) in the search for the relevant knowledge from the subjacent decision making process.

The remainder of this paper is structured as follows: Sect. 2 describes the problem, defines the group tolerance distribution and analyses its statistical properties; Sect. 3 presents decisional tools for exploiting (using a cognitive perspective) the information provided by the tolerance distribution; Sect. 4 applies the tools to the multiplicative model with lognormal errors conventionally used in the stochastic AHP; Sect. 5 illustrates the procedure with a case study; Sect. 6 sets out the main conclusions and offers some possibilities for future research.

\section{Tolerance distribution}

\subsection{Problem formulation}

Assuming a set of $n$ alternatives $\left\{\mathrm{A}_{1}, \ldots, \mathrm{A}_{\mathrm{n}}\right\}$ in a local context (a single criterion), let $\mathbf{D}=\left\{\mathrm{D}_{1}, \ldots, \mathrm{D}_{\mathrm{K}}\right\}$ be a group of $\mathrm{K}$ decision makers $(K \geq 2)$ and let $\mathrm{D}_{0}$ be the supra decision maker (analyst) in charge of solving the problem. Let $\left\{\alpha_{\mathrm{k}} ; \mathrm{k}=1, \ldots, \mathrm{K}, \alpha_{\mathrm{k}}>0 ; \sum_{\mathrm{k}=1}^{\mathrm{K}} \alpha_{\mathrm{k}}=\right.$ $1\}$ be a set of weights fixed by $D_{0}$ that reflects the relative importance of each decision maker $\mathrm{D}_{1}, \ldots, \mathrm{D}_{\mathrm{K}}$ in the joint decision making process.

To solve the group decision making problem using AHP, the decision makers $\left\{D_{1}, \ldots, D_{K}\right\}$ express their preferences by means of $\mathrm{K}$ reciprocal pairwise comparison matrices $\left\{\mathbf{R}^{(\mathrm{k})}, \mathrm{k}=\right.$ $1, \ldots, \mathrm{K}\}$. Without loss of generality and with the aim of simplifying the notation, it is assumed that $\mathbf{R}_{\mathrm{nxn}}^{(\mathrm{k})}=\left(\mathrm{r}_{\mathrm{ij}}^{(\mathrm{k})}\right)$ is a complete reciprocal positive square matrix (nxn), where $r_{i i}^{(k)}=1, r_{j i}^{(k)}=\frac{1}{r_{i j}^{(k)}}>0$ for $i, j=1, \ldots, n$.

The judgements $r_{i j}^{(k)}$ represent the relative preference between alternatives $i$ and $j$ for the decision maker $\mathrm{D}_{\mathrm{k}}$, according to Saaty's fundamental scale (Saaty 1980). Despite the fact that the "reference" points of the categories (equal, moderate, strong, very strong and extreme) used in this scale are a discrete set $\{1 / 9, \ldots, 1 / 2,1,2, \ldots, 9\}$, the judgements considered in this proposal belong to the continuous interval $[1 / 9,9]$.

Let $\left\{\mathbf{v}^{(\mathrm{k})}=\left(\mathrm{v}_{1}^{(\mathrm{k})}, \ldots, \mathrm{v}_{\mathrm{n}}^{(\mathrm{k})}\right)^{\prime} ; \mathrm{k}=1, \ldots, \mathrm{K}\right\},\left(\mathrm{v}_{1}^{(\mathrm{k})}>0, \ldots, \mathrm{v}_{\mathrm{n}}^{(\mathrm{k})}>0\right)$ be the individual's (unnormalised) priorities of the alternatives for each decision maker and let $\left\{\mathbf{w}^{(\mathrm{k})}=\left(\mathrm{w}_{1}^{(\mathrm{k})}\right.\right.$ 
$\left.\left.\mathrm{w}_{\mathrm{n}}^{(\mathrm{k})}\right)^{\prime} ; \mathrm{k}=1, \ldots, \mathrm{K}\right\}$ be their normalised values according to a distributive mode: $\mathrm{w}_{\mathrm{i}}^{(\mathrm{k})}=\frac{\mathrm{v}_{\mathrm{i}}^{(\mathrm{k})}}{\sum_{\mathrm{i}=1}^{\mathrm{n}} \mathrm{v}_{\mathrm{i}}^{(\mathrm{k})}}, \mathrm{i}=1, \ldots, \mathrm{n}$ with $\sum_{\mathrm{i}=1}^{\mathrm{n}} \mathrm{w}_{\mathrm{i}}^{(\mathrm{k})}=1, \mathrm{k}=1, \ldots, \mathrm{K}$.

Let us adopt a stochastic approach for AHP, and assume that the judgements $\left(\mathrm{r}_{\mathrm{ij}}^{(\mathrm{k})}\right)$ elicited by the decision makers $D_{k}, k=1, \ldots, K$ can be described by means of general Bayesian models

$$
\mathrm{g}_{\mathrm{k}}\left(\mathbf{r}^{(\mathrm{k})}, \mathbf{w}^{(\mathrm{k})}, \boldsymbol{\theta}^{(\mathrm{k})}\right)=f_{\mathrm{k}}\left(\mathbf{r}^{(\mathrm{k})} \mid \mathbf{w}^{(\mathrm{k})}, \boldsymbol{\theta}^{(\mathrm{k})}\right) \pi_{\mathrm{k}}\left(\mathbf{w}^{(\mathrm{k})}, \boldsymbol{\theta}^{(\mathrm{k})}\right), \mathrm{k}=1, \ldots, \mathrm{K}
$$

where $\mathbf{r}^{(\mathrm{k})}=\left(\mathrm{r}_{\mathrm{ij}}^{(\mathrm{k})} ; 1 \leq \mathrm{i}<\mathrm{j} \leq \mathrm{n}\right)^{\prime}$ is the judgements vector, $\mathrm{f}_{\mathrm{k}}\left(\mathbf{r}^{(\mathrm{k})} \mid \mathbf{w}^{(\mathrm{k})}, \boldsymbol{\theta}^{(\mathrm{k})}\right)$ is the likelihood function of the model, $\mathbf{w}^{(\mathrm{k})}$ is the priorities vector of decision maker $D_{k}, \theta^{(\mathrm{k})}$ is a vector of nuisance parameters (usually related to the inconsistency level of each decision maker, see Sect. 4), $\pi_{\mathrm{k}}\left(\mathbf{w}^{(\mathrm{k})}, \boldsymbol{\theta}^{(\mathrm{k})}\right)$ is the prior distribution of these parameters and $g_{k}\left(\mathbf{r}^{(\mathrm{k})}, \mathbf{w}^{(k)}, \boldsymbol{\theta}^{(k)}\right)$ the joint distribution of judgements and parameters.

Applying Bayes Theorem, the inferences about the priority vectors $\mathbf{w}^{(\mathrm{k})}$ would be made from their posterior distribution given by the expression:

$$
\pi_{\mathrm{k}}\left(\mathbf{w}^{(\mathrm{k})} \mid \mathbf{r}^{(\mathrm{k})}\right)=\frac{\int \mathrm{g}_{\mathrm{k}}\left(\mathbf{r}^{(\mathrm{k})}, \mathbf{w}^{(\mathrm{k})}, \boldsymbol{\theta}^{(\mathrm{k})}\right) \mathrm{d} \boldsymbol{\theta}^{(\mathrm{k})}}{\int \mathrm{g}_{\mathrm{k}}\left(\mathbf{r}^{(\mathrm{k})}, \mathbf{w}^{(\mathrm{k})}, \boldsymbol{\theta}^{(\mathrm{k})}\right) \mathrm{d} \mathbf{w}^{(\mathrm{k})} \mathrm{d} \boldsymbol{\theta}^{(\mathrm{k})}} ; \mathrm{k}=1, \ldots, \mathrm{K}
$$

Note that if some of the matrices $\mathbf{R}^{(\mathrm{k})}$ are incomplete, the mathematical calculus should be modified in an appropriate manner, taking into account that the posterior distribution (2) must be proper.

Distribution (2) contains, for each decision maker $D_{k}$, the relevant information on the priorities, $\mathbf{w}^{(\mathrm{k})}$, which reflects their preferences on the alternatives $\left\{\mathrm{A}_{1}, \ldots, \mathrm{A}_{n}\right\}$ of the problem. From this distribution, point estimations and Bayesian credibility intervals of $\mathbf{w}^{(\mathrm{k})}$ can be calculated, respectively, by using the posterior mean or median of the components and the appropriate quantiles. Furthermore, using Roy's decisional problem taxonomy (Roy 1985), inference about the best alternative (P. $\alpha$ problem), the second best (P. $\alpha$ 2) problem), the two best alternatives (P. $\alpha 1,2)$ problem) and the preferred preference structure (P. $\gamma$ problem) can be made using their corresponding posterior distributions and the posterior probabilities of rank reversal can also be obtained (Altuzarra et al. 2010, 2013).

The information about the relevant aspects of the decision making process allows the extraction of the knowledge from the cognitive perspective that are followed in the resolution of the problem (Moreno-Jiménez et al. 2001; Moreno-Jiménez 2003a). This information can also be very useful to initiate a subsequent tolerance process that concludes with a collective decision accepted by the majority of the actors involved in the resolution process. In the following section the tolerance distribution is defined and its properties are analysed.

\subsection{Tolerance distribution for a set of decision makers}

In order to solve the decision problem, it is assumed that $\mathrm{D}_{0}$ acts under a principle of tolerance where a permissive and democratic attitude toward the different visions and preferences of decision makers in $\mathbf{D}$ (expressed by their individual distributions $\left\{\pi_{\mathrm{k}} ; \mathrm{k}=1, \ldots, \mathrm{K}\right\}$ ) is adopted. Therefore, a collective probability distribution which highlights the priority vectors $\mathbf{w}$ that are well supported, i.e. have a non-negligible density value $\pi_{\mathrm{k}}(\mathbf{w})$, for all the members of the collective is sought and the following definition is introduced: 
Definition 2.1 The Tolerance Distribution for $\mathbf{D}$ is defined as the probability distribution given by:

$$
\pi_{\mathrm{tol}}\left(\mathbf{w} \mid\left\{\pi_{\mathrm{k}}\right\}_{\mathrm{k}=1}^{\mathrm{K}}\right) \alpha \prod_{\mathrm{k}=1}^{\mathrm{K}}\left[\pi_{\mathrm{k}}(\mathbf{w})\right]^{\alpha_{\mathrm{k}}}
$$

where $\pi_{k}(\mathbf{w})=\pi_{k}\left(\mathbf{w} \mid \mathbf{r}^{(k)}\right)$ for $k=1, \ldots, K$.

The following proposition proves that the tolerance distribution is well defined.

Proposition 2.1 Assuming that $\left\{\pi_{k}(\mathbf{w}) ; \mathrm{k}=1, \ldots, \mathrm{K}\right\}$ are proper probability distributions with their respective supports $\mathrm{SUPP}_{\mathrm{k}} \subseteq \mathrm{S}_{\mathrm{n}}=\left\{\mathbf{w}=\left(w_{1}, \ldots, w_{\mathrm{n}}\right)^{\prime}: \mathrm{w}_{\mathrm{i}} \geq 0 ; \mathrm{i}=1, \ldots, \mathrm{n}\right.$; $\left.\sum_{\mathrm{i}=1}^{\mathrm{n}} \mathrm{w}_{\mathrm{i}}=1\right\}$; and to avoid dogmatic positions among the decision makers of $\mathbf{D}$, that $S U P P=$ $\bigcap_{\mathrm{k}=1}^{\mathrm{K}} S U P P_{\mathrm{k}}$ is not a null measure set, then the tolerance distribution is proper and its support is SUPP.

Proof It is sufficient to show that this is a density function; firstly, it is not negative because each density $\left\{\pi_{k}(\mathbf{w}) ; \mathrm{k}=1, \ldots, \mathrm{K}\right\}$ is not negative, and SUPP $\neq \varnothing$ because it is not null measure. In addition, it is a proper density (Davidson 1994: Corollary 9.26) as:

$$
0<\int \prod_{\mathrm{k}=1}^{\mathrm{K}}\left[\pi_{\mathrm{k}}(\mathbf{w})\right]^{\alpha_{\mathrm{k}}} \mathrm{d} \mathbf{w} \leq \prod_{\mathrm{k}=1}^{\mathrm{K}}\left(\int \pi_{\mathrm{k}}(\mathbf{w}) \mathrm{d} \mathbf{w}\right)^{\alpha_{\mathrm{k}}}=1
$$

Remark 2.1 The tolerance distribution aims to incorporate the opinion of all the actors implicated in the resolution process. The density of the tolerance distribution $\pi_{\mathrm{tol}}$ will be higher for those priority vectors $\mathbf{w}$ that are well supported, i.e. have a non-negligible density value $\pi_{\mathrm{k}}(\mathbf{w})$, for all the members of the collective. In contrast, if a priority vector $\mathbf{w}$ is rejected by at least one of the actors (i.e. $\pi_{\mathrm{k}}(\mathbf{w}) \approx 0$ for at least one $\mathrm{k}$ ) then $\mathbf{w}$ will tend to be rejected by the tolerance distribution even though $\mathbf{w}$ will be well supported by the rest of the collective. The tolerance distribution will provide a probability distribution that is more democratic and in accordance with the tolerance principle, by highlighting those $\mathbf{w}$ where there is a greater probability of reaching a final agreement for all the members of $\mathbf{D}$.

Furthermore, the tolerance distribution is a synthesis (weighted geometric mean) of the individual preferences of the decision makers of $\mathbf{D}$, which is optimal in the following sense.

Definition 2.2 Let $\pi(\mathbf{w})$ and $\left\{\pi_{\mathrm{k}}(\mathbf{w}) ; \mathrm{k}=1, \ldots, \mathrm{K}\right\}$ be a set of $(1+\mathrm{K})$ probability distributions of $\mathbf{w}$. The Collective Kullback-Leibler $(C K L)$ distance is defined as the distance between $\mathrm{d}$ and the set $\left\{\pi_{\mathrm{k}}(\mathbf{w}) ; \mathrm{k}=1, \ldots, \mathrm{K}\right\}$ as the weighted arithmetic mean of the individual $\mathrm{KL}$ distances given by:

$$
\operatorname{CKL}\left(\pi\left\{\pi_{k}\right\}_{k=1}^{K}\right)=D\left(\pi\left\{\pi_{k}\right\}_{k=1}^{K}\right)=\sum_{k=1}^{K} \alpha_{k} \operatorname{KL}\left(\pi, \pi_{k}\right),
$$

where $\operatorname{KL}\left(\pi, \pi_{\mathrm{k}}\right)=\int \log \left(\frac{\pi(\mathbf{w})}{\pi_{\mathrm{k}}(\mathbf{w})}\right) \pi(\mathbf{w}) \mathrm{d} \mathbf{w}$ is the Kullback-Leibler distance between $\pi$ and $\pi_{\mathrm{k}}, \mathrm{k}=1, \ldots, \mathrm{K}$.

Theorem 2.1 The tolerance distribution $\pi_{\mathrm{tol}}$ defined in (3) minimises the CKL distance (4).

\section{Springer}


Proof Given that

$$
\begin{aligned}
& \operatorname{CKL}\left(\pi\left\{\pi_{\mathrm{k}}\right\}_{\mathrm{k}=1}^{\mathrm{K}}\right)=\sum_{\mathrm{k}=1}^{\mathrm{K}} \int \log \left(\frac{[\pi(\mathbf{w})]^{\alpha_{\mathrm{k}}}}{\left[\pi_{\mathrm{k}}(\mathbf{w})\right]^{\alpha_{\mathrm{k}}}}\right) \pi(\mathbf{w}) \mathrm{d} \mathbf{w}=\int \log \left(\frac{\prod_{\mathrm{k}=1}^{\mathrm{K}}[\pi(\mathbf{w})]^{\alpha_{\mathrm{k}}}}{\prod_{\mathrm{k}=1}^{\mathrm{K}}\left[\pi_{\mathrm{k}}(\mathbf{w})\right]^{\alpha_{\mathrm{k}}}}\right) \pi(\mathbf{w}) \mathrm{d} \mathbf{w}= \\
& =\int \log \left(\frac{\pi(\mathbf{w})}{\prod_{\mathrm{k}=1}^{\mathrm{K}\left[\pi_{\mathrm{k}}(\mathbf{w})\right]^{\alpha_{\mathrm{k}}}}}\right) \pi(\mathbf{w}) \mathrm{d} \mathbf{w}=\mathrm{KL}\left(\pi, \pi_{\mathrm{tol}}\right)+\mathrm{C}
\end{aligned}
$$

where $\mathrm{C}=-\log \left(\int \prod_{\mathrm{k}=1}^{\mathrm{K}}\left[\pi_{\mathrm{k}}(\mathbf{w})\right]^{\alpha_{\mathrm{k}}}\right) \mathrm{d} \mathbf{w}$ does not depend on $\mathrm{d}$. From (5), it follows that $\operatorname{Min}_{\pi} \operatorname{CKL}\left(\pi,\left\{\pi_{\mathrm{k}}\right\}_{\mathrm{k}=1}^{\mathrm{K}}\right) \equiv \operatorname{Min}_{\pi} \mathrm{KL}\left(\pi, \pi_{\mathrm{tol}}\right)=\mathrm{KL}\left(\pi_{\mathrm{tol}}, \pi_{\mathrm{tol}}\right)=0$.

Remark 2.2 The CKL distance (4) adopts the point of view of a supra decision maker who looks to integrate the preferences of all the decision makers $\left\{\mathrm{D}_{\mathrm{k}} ; \mathrm{k}=1, \ldots, \mathrm{K}\right\}$ under a principle of tolerance (collective perspective). According to this principle (permissive attitude towards individual preferences), the CKL distance takes the collective distribution $\mathrm{d}$ as the anchor with respect to the individual distributions $\left\{\pi_{\mathrm{k}}\right\}_{\mathrm{k}=1}^{\mathrm{K}}$ that are compared. This, and the fact that the KL distance is not symmetric, justify that the selected KL distance was $\mathrm{KL}\left(\pi, \pi_{\mathrm{k}}\right)$ and not $\operatorname{KL}\left(\pi_{\mathrm{k}}, \pi\right)$. The last distance adopts an individual perspective in the sense that each decision maker considers its individual distribution $\pi_{\mathrm{k}}$ as the anchor and compares the collective distribution $\pi$ with respect to it. This favours the selection of collective distributions where the decision makers with greater influence will impose their opinions. In fact, if we consider the collective distance given by

$$
\operatorname{CKL}_{1}\left(\left\{\pi_{\mathrm{k}}\right\}_{\mathrm{k}=1}^{\mathrm{K}}, \pi\right)=\mathrm{D}_{1}\left(\left\{\pi_{\mathrm{k}}\right\}_{\mathrm{k}=1}^{\mathrm{K}}, \pi\right)=\sum_{\mathrm{k}=1}^{\mathrm{K}} \alpha_{\mathrm{k}} \operatorname{KL}\left(\pi_{\mathrm{k}}, \pi\right)
$$

it can be proved that its minimum is achieved in the mixture $\pi=\sum_{\mathrm{k}=1}^{\mathrm{K}} \alpha_{\mathrm{k}} \pi_{\mathrm{k}}$ where the decision makers with larger weights $\alpha_{k}$ will be more determinant in the selection of the joint priority vector $\mathbf{w}$.

To conclude this analysis of the tolerance distribution, it is worth mentioning that it is essentially unique and invariant to re-parameterisations of the priority vector $\mathbf{w}$, as shown by the following proposition:

Proposition 2.2 Let $\mathbf{v}=\mathrm{h}(\mathbf{w})$ be a one-to-one re-parameterisation of the priorities vector w. Then

$$
\pi_{\text {tol }}\left(\mathbf{v} \mid\left\{\pi_{\mathrm{k}}\right\}_{\mathrm{k}=1}^{\mathrm{K}}\right) \propto \prod_{\mathrm{k}=1}^{\mathrm{K}}\left[\pi_{\mathrm{k}}(\mathbf{v})\right]^{\alpha_{\mathrm{k}}}
$$

$\left\{\pi_{\mathrm{k}}(\mathbf{v}) ; \mathrm{k}=1, \ldots, \mathrm{r}\right\}$ are the individual distributions obtained from the distributions (2) by the transformation $\mathbf{v}=\mathrm{h}(\mathbf{w})$.

Proof If $\left|\frac{\mathrm{d} \mathbf{w}}{\mathrm{d} \mathbf{v}}\right|$ denotes the Jacobian of the transformation $\mathbf{w}=\mathrm{h}^{-1}(\mathbf{v})$ it is therefore verified that:

$$
\begin{aligned}
\pi_{\mathrm{tol}}\left(\mathbf{v} \mid\left\{\pi_{\mathrm{k}}\right\}_{\mathrm{k}=1}^{\mathrm{K}}\right) & \propto \pi_{\mathrm{tol}}(\mathbf{w})\left|\frac{\mathrm{d} \mathbf{w}}{\mathrm{d} \mathbf{v}}\right|=\prod_{\mathrm{k}=1}^{\mathrm{K}}\left[\pi_{\mathrm{k}}(\mathbf{w})\right]^{\alpha_{\mathrm{k}}}\left|\frac{\mathrm{d} \mathbf{w}}{\mathrm{d} \mathbf{v}}\right|= \\
& =\prod_{\mathrm{k}=1}^{\mathrm{K}}\left[\pi_{\mathrm{k}}(\mathbf{w})\left|\frac{\mathrm{d} \mathbf{w}}{\mathrm{d} \mathbf{v}}\right|\right]^{\alpha_{\mathrm{k}}}=\prod_{\mathrm{k}=1}^{\mathrm{K}}\left[\pi_{\mathrm{k}}(\mathbf{v})\right]^{\alpha_{\mathrm{k}}}
\end{aligned}
$$




\section{Knowledge extraction from the tolerance distribution}

As demonstrated in Sect. 2, the tolerance distribution provides a synthesis of the individual priority vector distributions and highlights the priority vectors that are compatible with the judgements elicited by the members of the group. For these reasons it seems logical to use it to construct decisional tools that favour the extraction of knowledge related with the scientific resolution of the decision problem. The following section describes several of these tools, depending on the problem that is to be resolved.

\subsection{Selection of the best alternative}

For the selection of the best alternative, known in the literature as the P. $\alpha$ problem (Roy 1985), it is possible to use the distribution of the most preferred alternative $A_{(1)}$, a discrete distribution with support $\left\{\mathrm{A}_{1}, \ldots, \mathrm{A}_{\mathrm{n}}\right\}$ and a probability function given by:

$$
\begin{aligned}
P\left(A_{(1)}=A_{i}\right) & =P\left(w_{i}=\max _{1 \leq j \leq n}\left\{w_{j}\right\}\right) \\
& =\int_{\left\{w_{w}: w_{i}=\max _{1 \leq j \leq n}\left\{w_{j}\right\}\right\}} \pi_{\text {tol }}(\mathbf{w}) d \mathbf{w} ; i=1, \ldots, n
\end{aligned}
$$

The best alternative will be that which maximises the probabilities (8).

\subsection{Selection of the k-best alternatives}

Generalising the previous idea (8), the $\mathrm{k}$ most preferred alternatives can be determined by using the joint distribution of the $\mathrm{k}$ first alternatives $\left(\mathrm{A}_{(1)}, \mathrm{A}_{(2)}, \ldots, \mathrm{A}_{(\mathrm{k})}\right)$ where $\mathrm{A}_{(\mathrm{j})}$ denotes the $\mathrm{j}$-th most preferred alternative for $\mathrm{j}=1, \ldots, \mathrm{k}$. In particular, taking $\mathrm{k}=\mathrm{n}$ the distribution of the preference structures (Moreno-Jiménez and Vargas 1993) used to select the most preferred ranking of alternatives can also be determined; a problem that is known in the literature as a gamma type problem or P. $\gamma$ problem.

These distributions can be employed for the analysis of the most preferred and the most rejected alternatives and this is information that can be very valuable for designing strategies (tolerance paths) to achieve more democratic or representative decision processes.

\subsection{Pairwise dominance probability matrix}

The Pairwise Dominance Probabilities Matrix (PDPM) given by Altuzarra et al. (2013) can be very useful for analysing the knowledge extraction process:

\section{Springer}




$$
\begin{aligned}
& P\left(A_{i} \succ A_{j}\right)=P\left(w_{i}>w_{j}\right)+\frac{1}{2} P\left(w_{i}=w_{j}\right)= \\
& \quad=\int_{\left\{w_{\text {w }}>w_{j}\right\}} \pi_{\text {tol }}(\mathbf{w}) d \mathbf{w}+\frac{1}{2} \int_{\left\{w_{i}=w_{j}\right\}} \pi_{t o l}(\mathbf{w}) d \mathbf{w} ; 1 \leq \mathrm{i} \neq \mathrm{j} \leq \mathrm{n} \\
& P(A i \succ A i)=1
\end{aligned}
$$

where $A_{i} \succ A_{j}$ means " $A_{i}$ is as least as preferred as $A_{j}$ ".

From these probabilities, the rankings of alternatives can be established that take into account, not only the two first positions, but also if they are located in any other places compatible with the dominance criterion " $\succ$ " (Altuzarra et al. 2013). The consideration of this information will increase the robustness of the ranking that is ultimately selected. This information should also be used to evaluate the representativeness of the tolerance distribution.

\section{Tolerance distribution in AHP multiplicative models with logarithmic-normal errors}

This section contemplates the multiplicative model with logarithm-normal errors usually employed in the stochastic analysis of AHP (Ramsay 1977; Genest and Rivest 1994; Alho and Kangas 1997; Laininen and Hämäläinen 2003, Altuzarra et al. 2007, 2010) which will be used to illustrate the methodology described in the previous sections. However, it is worth noting that other kinds of Bayesian models can also be used, for example, the categorical data models proposed by Hahn $(2003,2006)$.

In this case, the individual models are given by the expressions:

$$
r_{i j}^{(k)}=\frac{v_{i}^{(k)}}{v_{j}^{(k)}} e_{i j}^{(k)}, \quad i=1, \ldots, n-1 ; j=i+1, \ldots, n ; k=1, \ldots, K
$$

where we assume that $\left\{\mathrm{e}_{\mathrm{ij}}^{(\mathrm{k})} ; \mathrm{i}=1, \ldots, \mathrm{n}-1 ; \mathrm{j}=\mathrm{i}+1, \ldots, \mathrm{n} ; \mathrm{k}=1, \ldots, \mathrm{K}\right\}$ are independent errors with $\mathrm{e}_{\mathrm{ij}}^{(\mathrm{k})} \sim \operatorname{LN}\left(0, \sigma^{(\mathrm{k}) 2}\right)$, being $\mathrm{LN}\left(\mu, \sigma^{2}\right)$ the log-normal distribution with location parameter $\mu$ and scale parameter $\sigma^{2}$.

Taking these logarithms, we have a regression model with normal errors given by the equations:

$$
y_{i j}^{(k)}=\mu_{i}^{(k)}-\mu_{j}^{(k)}+\varepsilon_{i j}^{(k)} ; i=1, \ldots, n-1 ; j=i+1, \ldots, n ; k=1, . ., K
$$

where $\mathrm{y}_{\mathrm{ij}}^{(\mathrm{k})}=\log \left(\mathrm{r}_{\mathrm{ij}}^{(\mathrm{k})}\right), \mu_{\mathrm{i}}^{(\mathrm{k})}=\log \left(\mathrm{v}_{\mathrm{i}}^{(\mathrm{k})}\right)$ and $\varepsilon_{\mathrm{ij}}^{(\mathrm{k})}=\log \left(\mathrm{e}_{\mathrm{ij}}^{(\mathrm{k})}\right) \sim \mathrm{N}\left(0, \sigma^{(\mathrm{k}) 2}\right)$ for $\mathrm{k}=$ $1, \ldots, K$. In addition, and in order to avoid identification problems, we take $\mu_{n}=0$, that is to say, we take $A_{n}$ as a reference alternative.

Let $\mathbf{y}^{(\mathrm{k})}=\left(\mathrm{y}_{12}^{(\mathrm{k})}, \mathrm{y}_{13}^{(\mathrm{k})}, \ldots, \mathrm{y}_{\mathrm{n}-1 \mathrm{n}}^{(\mathrm{k})}\right)^{\prime}$ be the vector of judgements elicited by the decision maker $D_{k}, k=1, \ldots, K$, and let $J=\frac{n(n-1)}{2}$ be the number of these judgements.

Let $\mathbf{X}=\left(\mathrm{x}_{\mathrm{ij}}\right)$ be the $\mathrm{Jx}(\mathrm{n}-1)$ matrix in such a way that if the $\mathrm{i}^{\text {th }}$ component of these vectors $\left\{\mathbf{y}^{(\mathrm{k})} ; \mathrm{k}=1, \ldots, \mathrm{K}\right\}$ corresponds to the comparison among alternatives $\mathrm{A}_{\mathrm{j}}$ and $\mathrm{A}_{\ell}$ with $1 \leq \mathrm{j}<\ell<\mathrm{m}_{\text {then }} \mathrm{x}_{\mathrm{ij}}=1, \mathrm{x}_{\mathrm{i} \ell}=-1$ and $\mathrm{x}_{\mathrm{is}}=0$ for $\mathrm{s} \neq \mathrm{j}, \ell$, and if the $\mathrm{i}^{\text {th }}$ component corresponds to a comparison between the alternatives $A_{j} 1 \leq j<n$ and $A_{n}$, then $x_{i j}=1$ and $\mathrm{x}_{\mathrm{is}}=0$ for $\mathrm{s} \neq \mathrm{j}$.

Equation (11) can be written in a matrix form as:

$$
\mathbf{y}^{(\mathrm{k})}=\mathbf{X} \boldsymbol{\mu}^{(\mathrm{k})}+\stackrel{(\mathrm{k})}{\varepsilon} ; \mathrm{k}=1, \ldots, \mathrm{K}
$$

with $\boldsymbol{\varepsilon}^{(\mathrm{k})}=\left(\varepsilon_{12}^{(\mathrm{k})}, \varepsilon_{13}^{(\mathrm{k})}, \ldots, \varepsilon_{\mathrm{n}-1 \mathrm{n}}^{(\mathrm{k})}\right)^{\prime} \sim \mathrm{N}_{\mathrm{J}}\left(\mathbf{0}_{\mathrm{J}}, \sigma^{(\mathrm{k}) 2} \mathbf{I}_{\mathrm{J}}\right)$ and $\mathbf{I}_{\mathrm{J}}$ is the JXJ identity matrix. 
It must be decided if the error variances are known or unknown. In the first case, it is possible to calculate exactly the tolerance distribution, whilst in the second case, the tolerance distribution is analytically intractable and Monte Carlo methods are employed. A general procedure to obtain a sample of this distribution is provided below.

\subsection{Tolerance distribution with known variances}

If the variances of the error terms $\left\{\sigma^{(1) 2}, \ldots, \sigma^{(\mathrm{K}) 2}\right\}$ are known, and we take the noninformative uniform distribution in $\mathbf{R}^{\mathrm{n}-1}$ as the prior distribution on $\boldsymbol{\mu}^{(\mathrm{k})}=\left(\mu_{1}^{(\mathrm{k})}, \ldots, \mu_{n-1}^{(\mathrm{k})}\right)^{\prime}$ (Gelman et al. 2004; Altuzarra et al. 2007), the posterior distributions of $\left\{\boldsymbol{\mu}^{(\mathrm{k})} ; \mathrm{k}=1, \ldots, \mathrm{K}\right\}$ are given by:

$$
\boldsymbol{\mu}^{(\mathrm{k})} \mid \mathbf{y}^{(\mathrm{k})} \sim \mathrm{N}_{\mathrm{n}-1}\left(\hat{\boldsymbol{\mu}}^{(\mathrm{k})}, \sigma^{(\mathrm{k}) 2}\left(\mathbf{X}^{\prime} \mathbf{X}\right)^{-1}\right)
$$

where $\hat{\mu}^{(\mathrm{k})}=\left(\mathbf{X}^{\prime} \mathbf{X}\right)^{-1}\left(\mathbf{X}^{\prime} \mathbf{y}^{(\mathrm{k})}\right)$.

Using standard calculus and Proposition $2.2(\mu=h(\mathbf{w})=\log \mathbf{w})$, the tolerance distribution (3) will be given by:

$$
\pi_{\mathrm{tol}}(\mu) \alpha \prod_{\mathrm{k}=1}^{\mathrm{K}}\left[\pi_{\mathrm{k}}(\mu)\right]^{\alpha_{\mathrm{k}}} \sim \mathrm{N}_{\mathrm{n}-1}\left(\hat{\mu}, \hat{\sigma}^{2}\left(\mathbf{X}^{\prime} \mathbf{X}\right)^{-1}\right)
$$

$$
\text { where } \pi_{k}(\mu) \text { is given by (4.4) and } \hat{\mu}=\frac{\sum_{\mathrm{k}=1}^{\mathrm{K}} \frac{\alpha_{\mathrm{k}}}{\sigma^{(\mathrm{k}) 2} \hat{\mu}^{(\mathrm{k})}}}{\sum_{\mathrm{k}=1}^{\mathrm{K}} \frac{\alpha_{\mathrm{k}}}{\sigma^{(\mathrm{k}) 2}}} \text { and } \hat{\sigma}^{2}=\frac{1}{\sum_{\mathrm{k}=1}^{\mathrm{K}} \frac{\alpha_{\mathrm{k}}}{\sigma^{(\mathrm{k}) 2}}} \text {. }
$$

Altuzarra et al. (2007) proved that $\hat{\mu}$ (the posterior mean of the tolerance distribution of the parameter $\boldsymbol{\mu}$ ) behaves better in terms of the mean square estimation error than the estimators of $\mu$ applying the aggregation of individual judgements (AIJ) and the aggregation of individual priorities (AIP) procedures traditionally considered in the literature.

Using (14) it is possible to make inferences about $\mathbf{w}$, as described in Sect. 2.1, and to calculate the probabilities presented in Sect. 3.

\subsection{Tolerance distribution with unknown variances}

Assuming the non-informative uniform distribution in $\mathbf{R}^{\mathrm{n}-1}$ as the prior distribution on $\mu^{(\mathrm{k})}=\left(\mu_{1}^{(\mathrm{k})}, \ldots, \mu_{\mathrm{n}-1}^{(\mathrm{k})}\right)^{\prime}$, and taking as prior distributions for the precisions " $\tau^{(\mathrm{k})} ; \mathrm{k}=$ $1, \ldots, \mathrm{K}$ the usual conjugates given by:

$$
\tau^{(\mathrm{k})}=\frac{1}{\sigma^{2(\mathrm{k})}} \sim \operatorname{Gamma}\left(\frac{\mathrm{n}_{0}}{2}, \frac{\mathrm{n}_{0} \mathrm{~s}_{0}^{2}}{2}\right) \mathrm{k}=1, \ldots, \mathrm{K} \text { with } \mathrm{n}_{0}, \mathrm{~s}_{0}^{2}>0
$$

with $\mathrm{n}_{0}$ small in order to make it diffuse and $\mathrm{s}_{0}^{2}$ equal to the desirable values of the inconsistency levels (Genest and Rivest 1994).

Standard calculations show that the individual posterior distributions are given by:

$$
\tau^{(\mathrm{k})} \mid \mathbf{y}^{(\mathrm{k})} \sim \operatorname{Gamma}\left(\frac{\mathrm{n}_{0}+\mathrm{J}-\mathrm{n}+1}{2}, \frac{\left(\mathrm{n}_{0}+\mathrm{J}-\mathrm{n}+1\right) \mathrm{s}^{2(\mathrm{k})}}{2}\right)
$$

$$
\boldsymbol{\mu}^{(\mathrm{k})} \mid \mathrm{y}^{(\mathrm{k})} \sim \mathrm{T}_{\mathrm{n}-1}\left(\hat{\boldsymbol{\mu}}^{(\mathrm{k})}, \mathrm{s}^{2(\mathrm{k})}\left(\mathbf{X}^{\prime} \mathbf{X}\right)^{-1}, \mathrm{n}_{0}+\mathrm{J}-\mathrm{n}+1\right), \mathrm{k}=1, \ldots, \mathrm{K} \text { independents }
$$

\section{黑 Springer}


where

$$
\hat{\boldsymbol{\mu}}^{(\mathrm{k})}=\left(\mathbf{X}^{\prime} \mathbf{X}\right)^{-1}\left(\mathbf{X}^{\prime} \mathbf{y}^{(\mathrm{k})}\right), \quad \mathrm{s}^{2(\mathrm{k})}=\frac{\mathrm{n}_{0} \mathrm{~s}_{0}^{2}+\left(\mathbf{y}^{(\mathrm{k})}-\mathbf{X} \hat{\boldsymbol{\mu}}^{(\mathrm{k})}\right)^{\prime}\left(\mathbf{y}^{(\mathrm{k})}-\mathbf{X} \hat{\boldsymbol{\mu}}^{(\mathrm{k})}\right)}{\mathrm{n}_{0}+\mathbf{J}-\mathrm{n}+1}
$$

and $T_{n}\left(\mu, \sigma^{2}, \nu\right)$ denotes the multivariate $n$-dimensional $T$ of Student ${ }^{1}$ with location parameter $\mu$, scale parameter $\sigma^{2}$ and $\nu$ degrees of freedom.

Taking into account (16), the tolerance distribution will be given by:

$$
\pi_{\mathrm{tol}}(\mu) \propto \prod_{\mathrm{k}=1}^{\mathrm{K}}\left[\pi_{\mathrm{k}}\left(\mu \mid \mathrm{y}^{(\mathrm{k})}\right)\right]^{\alpha_{\mathrm{k}}}=\prod_{\mathrm{k}=1}^{\mathrm{K}}\left[\mathrm{T}_{\mathrm{n}-1}\left(\hat{\mu}^{(\mathrm{k})}, \mathrm{s}^{2(\mathrm{k})}\left(\mathbf{X}^{\prime} \mathbf{X}\right)^{-1}, \mathrm{n}_{0}+\mathrm{J}-\mathrm{n}+1\right)(\mu)\right]^{\alpha_{\mathrm{k}}}
$$

This distribution is not a standard form and it is necessary to use Monte Carlo methods to calculate it. A general algorithm to solve this situation follows.

\subsubsection{Algorithm to draw a sample from the tolerance distribution}

This section describes a general procedure for obtaining a sample of the tolerance distribution. The procedure can be used when it is necessary to calculate analytically intractable probabilities, posterior moments, quantiles, etc. and it is possible to draw samples from the individual distributions $\left\{\pi_{\mathrm{k}}(\mathbf{w}) ; \mathrm{k}=1, \ldots, \mathrm{K}\right\}$. The process uses importance sampling and, more specifically, the sampling-importance re-sampling procedure or SIR (Rubin 1987), taking the mixture $\sum_{\mathrm{k}=1}^{\mathrm{K}} \alpha_{\mathrm{k}} \pi_{\mathrm{k}}(\mathbf{w})$ as an importance distribution. Note that this distribution has heavier tails than the tolerance distribution (3) and, therefore, the asymptotic results of Geweke (1989) can be applied.

\section{Algorithm 1 Extraction of samples from the tolerance distribution}

Step 0 Fix the number of simulations (S) and the number of samples ( $\left.\mathrm{S}^{\prime}\right)$

Step 1 Draw $S^{\prime}$ samples $\left(S^{\prime}>>S\right),\left\{\mathbf{u}^{(\mathrm{s})} ; \mathrm{s}=1, \ldots, \mathrm{S}^{\prime}\right\}$, from the mixture $\sum_{\mathrm{k}=1}^{\mathrm{K}} \alpha_{\mathrm{k}} \pi_{\mathrm{k}}(\mathbf{w})$ using, for example, a composition method.

Step 2 Assign importance weights $\left\{\beta^{(\mathrm{s})} ; \mathrm{s}=1, \ldots, \mathrm{S}^{\prime}\right\}$ to the sample $\left\{\mathbf{u}^{(\mathrm{s})} ; \mathrm{s}=1, \ldots, \mathrm{S}^{\prime}\right\}$ where:

$$
\beta^{(\mathrm{s})}=\frac{\prod_{\mathrm{k}=1}^{\mathrm{K}}\left[\pi_{\mathrm{k}}\left(\mathbf{u}^{(\mathrm{s})}\right)\right]^{\alpha_{\mathrm{k}}}}{\sum_{\mathrm{k}=1}^{\mathrm{K}} \alpha_{\mathrm{k}} \pi_{\mathrm{k}}\left(\mathbf{u}^{(\mathrm{s})} \mid \mathrm{r}^{(\mathrm{k})}\right)} ; \mathrm{s}=1, \ldots, \mathrm{S}^{\prime}
$$

Step 3 Draw $\mathrm{S}$ samples $\left\{\mathbf{w}^{(\mathrm{s})} ; \mathrm{s}=1, \ldots, \mathrm{S}\right\}$ from the discrete distribution $\left\{\left(\mathbf{u}^{(\mathrm{s})}, \mathrm{p}^{(\mathrm{s})}\right) ; \mathrm{s}=\right.$ $1, \ldots, \mathrm{KS}\}$ with $\mathrm{p}^{(\mathrm{s})}=\frac{\beta^{(\mathrm{s})}}{\sum_{\mathrm{i}=1}^{\mathrm{S}^{\prime}} \beta^{(\mathrm{i})}} ; \mathrm{s}=1, \ldots, \mathrm{S}^{\prime}$.

From these samples it is possible to make inferences about $\mathbf{w}$, as explained in Sect. 2.1, and to calculate the probabilities presented in Sect. 3 using their corresponding Monte Carlo estimates.

1 The stability of the priorities given by (16) against small judgement changes is guaranteed by having the $\mathrm{T}$ of Student with a reduced number of degrees of freedom (heavy-tailed distributions). 
Table 1 Pairwise comparison judgments for each decision maker

\begin{tabular}{lllllllll}
\hline $\mathrm{DM}$ & Type & Weights $(\%)$ & $\mathrm{r}_{12}$ & $\mathrm{r}_{13}$ & $\mathrm{r}_{14}$ & $\mathrm{r}_{23}$ & $\mathrm{r}_{24}$ & $\mathrm{r}_{34}$ \\
\hline $\mathrm{D}_{1}$ & Political & 10 & 1 & 5 & 3 & 6 & 5 & 1 \\
$\mathrm{D}_{2}$ & Political & 10 & 7 & 4 & 4 & $1 / 5$ & $1 / 5$ & 2 \\
$\mathrm{D}_{3}$ & Political & 10 & 9 & 1 & 7 & $1 / 7$ & 3 & 8 \\
$\mathrm{D}_{4}$ & Political & 10 & 7 & 2 & 7 & $1 / 5$ & $1 / 5$ & 5 \\
$\mathrm{D}_{5}$ & Association & 16 & $1 / 6$ & $1 / 3$ & $1 / 3$ & 3 & 3 & 1 \\
$\mathrm{D}_{6}$ & Association & 16 & 1 & 1 & 1 & 3 & 3 & 1 \\
$\mathrm{D}_{7}$ & Association & 4 & 9 & $1 / 2$ & 6 & $1 / 7$ & 1 & 8 \\
$\mathrm{D}_{8}$ & Association & 4 & 2 & 9 & 9 & 9 & 8 & 1 \\
$\mathrm{D}_{9}$ & Association & 8 & 9 & 7 & 7 & $1 / 3$ & $1 / 2$ & 1 \\
$\mathrm{D}_{10}$ & Citizen & 4 & 1 & 4 & 1 & 5 & 5 & 1 \\
$\mathrm{D}_{11}$ & Citizen & 4 & $1 / 2$ & 4 & 6 & 5 & 8 & 5 \\
$\mathrm{D}_{12}$ & Citizen & 4 & 4 & 9 & 9 & 9 & 9 & 1 \\
\hline
\end{tabular}

\section{Case study: e-participatory budgets}

The methodology is applied to a case study, adapted from a real-life experience (http://www. zaragoza.es/presupuestosparticipativos/ElRabal/) developed by the "Zaragoza Multicriteria Decision Making Group" (GDMZ) for the Zaragoza City Council (Spain). The experience was based on a new democratic system, known as e-cognocracy (Moreno-Jiménez 2003b, 2006; Moreno-Jiménez and Polasek 2003), applied to an e-participatory budget allocation problem. The budget that the municipal district of El Rabal (Zaragoza) assigns to each one of four alternatives proposed by the Neighbourhood Associations and the Members of the District Council was determined by using AHP as the multicriteria methodological support and Internet as the communication tool for the extraction of the individuals' preferences. The four alternatives were $(n=4)$ : $A_{1}$ : the Longares Avenue tunnel; $A_{2}$ : the renovation of Puente del Pilar Avenue; $\mathrm{A}_{3}$ : the shortening of Pacuala Peire Street; and $\mathrm{A}_{4}$ : the renovation of Ignacio Zapata Street. They were prioritised by taking into account a total of three criteria and six subcriteria.

The study contemplated the preferences elicited by 12 actors or decision makers ( 4 politicians, 5 representatives of neighbourhood associations and 3 citizens) with respect to one of the most important aspects of the problem (a local context ${ }^{2}$ ): the environmental subcriterion called "Prevention". A weighting was assigned to each decision maker, based on the number of citizens represented (the authors acted as the supra decision maker). The weightings and the pairwise preference judgements elicited by each of them are shown in Table 1. For each of the $\mathrm{K}=12$ decision makers, a $4 \times 4$ pairwise comparison matrix (six judgements) was obtained from the initial data. The matrices reflect the preferences of the actors between the four alternatives with respect to the single criterion (Prevention).

The methodology discussed in Sects. 2 and 3 was applied (assuming unknown variances) by taking $\mathrm{n}_{0}=0.0001$ and $\mathrm{s}_{0}=0.1^{3}$.

\footnotetext{
2 Extension to a global context (hierarchy) will be the subject of a future paper.

3 These values correspond to a diffuse prior centred on the level of inconsistency, as suggested by Genest and Rivest (1994).
} 


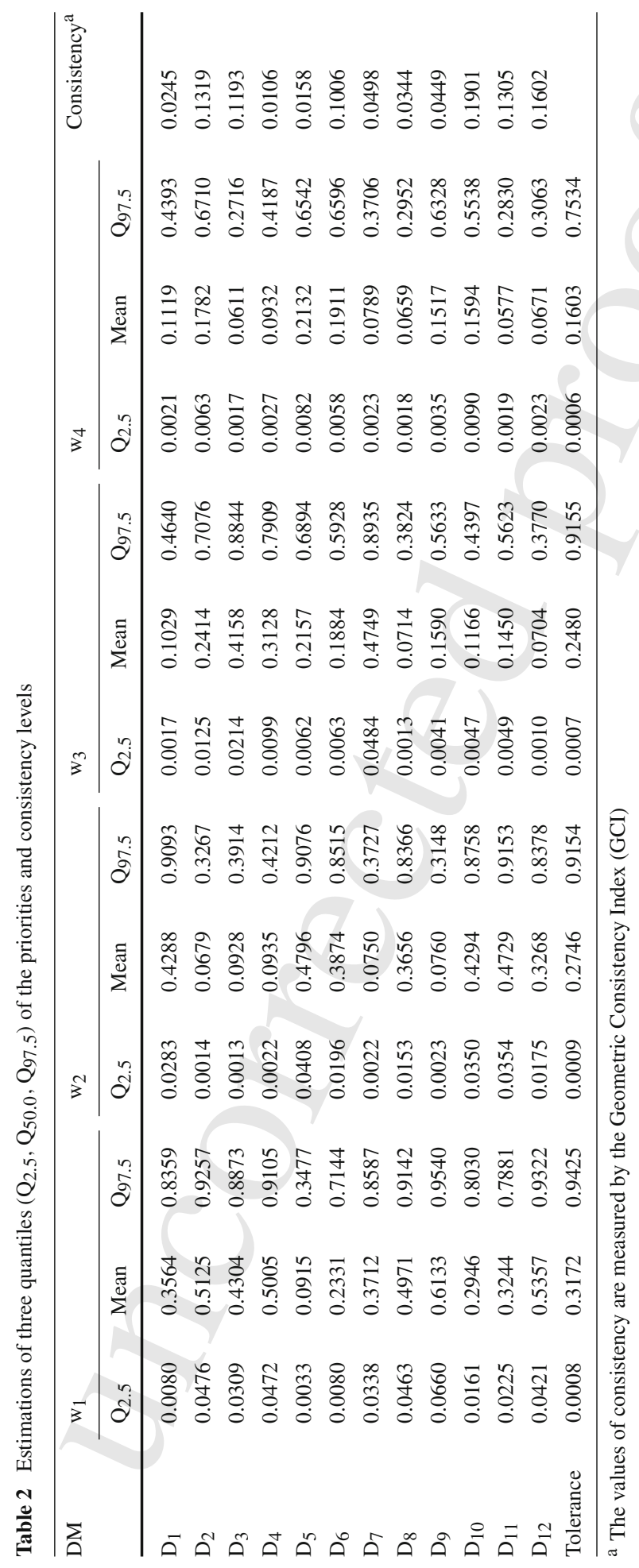




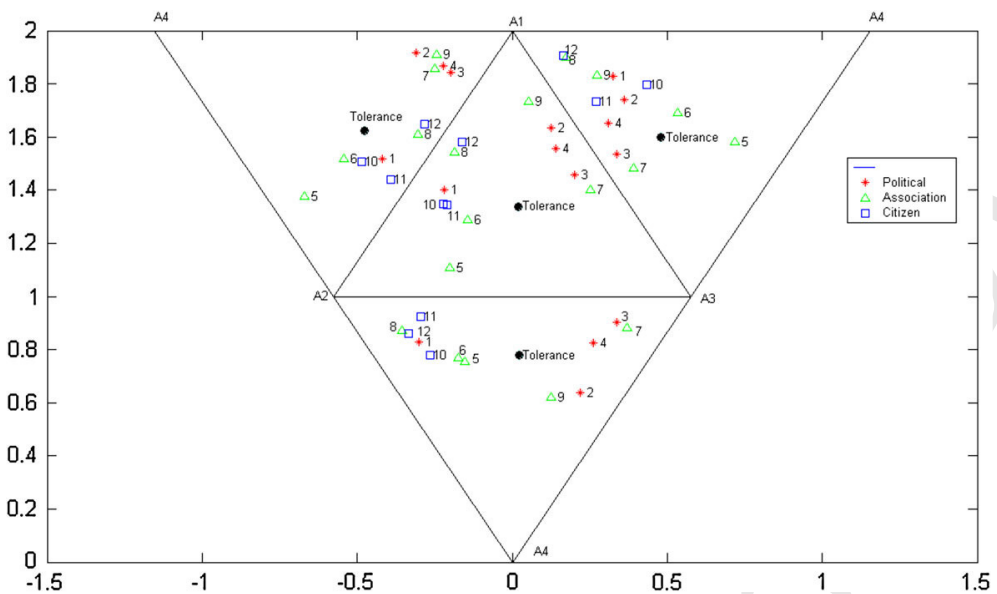

Fig. 1 Quaternary graph associated with the mean priorities of the decision makers and the tolerance distribution

\subsection{Individual priorities}

Table 2 shows the posterior means and the $95 \%$ Bayesian credibility intervals constructed from the posterior quantiles $2.5 \%\left(\mathrm{Q}_{2.5}\right)$ and $97.5 \%\left(\mathrm{Q}_{97.5}\right)$ of the individual priorities $\left\{\mathrm{w}_{\mathrm{i}}^{(\mathrm{k})} ; \mathrm{i}=1, \ldots, 4\right\}$ of each of the 12 decision makers and the posterior means of the variances $\left\{\sigma^{2(\mathrm{k})} ; \mathrm{k}=1, \ldots, 12\right\}$ that can be used to measure the individuals' levels of consistency. The consistency values in Table 2 have been measured by the Geometric Consistency Index $(\mathrm{GCI})$ and all of them fall under the permitted threshold $(0.35$ for $n=4)$. Figure 1 represents, by means of a quaternary graph (Aitchison 1986: p. 45, exercise 2.3), the posterior mean of the individual priorities and the tolerance distribution projected over the 4 different, 3 dimensional simplex; Fig. 2 shows the box plots of the individual posterior distributions of the decision makers' priorities and the tolerance distribution calculated from the samples of these distributions. All the moments and quantiles were calculated by using the Monte Carlo method (10000 simulations) from the individual posterior distributions (16).

Tables 3, 4 and 5 show the posterior distributions of the ordered alternatives, the two most preferred alternatives and the rankings of the alternatives for each decision maker. Table 6 presents the dominance probabilities (9) and Table 7 the posterior mean of the quotients of priorities $\frac{\mathrm{w}_{\mathrm{i}}}{\mathrm{w}_{\mathrm{j}}}$ for each pair of alternatives that measure the strength of the relative preference of the decision maker of $A_{i}$ over $A_{j}$ estimated by the priorities vector $\mathbf{w}$. These distributions were obtained by using the Monte Carlo method (10000 simulations) from the posterior distributions (16).

Figure 1 and the individual priorities of Table 2 show the existence of 4 groups of decision makers. The first group, with a total weight (representativeness) of $42 \%$ (Table 1), is formed by the decision makers $D_{2}, D_{3}, D_{4}, D_{7}$ and $D_{9}$, who seem to prefer alternatives $A_{1}$ and $A_{3}$ over the rest of alternatives. In this group the majority $\left(D_{2}, D_{3}, D_{4}\right.$ and $\left.D_{9}\right)$ show a higher preference for the alternative $A_{1}$ while $D_{7}$ prefers alternative $A_{3}$. The second group, with a total weight of $34 \%$, consists of the decision makers $\mathrm{D}_{1}, \mathrm{D}_{6}, \mathrm{D}_{10}$ and $\mathrm{D}_{11}$, who support alternatives $A_{2}$ as the most preferred and $A_{1}$ as the second most preferred. The third group, with a total weight of $16 \%$, is $\mathrm{D}_{5}$ who set alternative $\mathrm{A}_{2}$ as the most preferred; this individual clearly rejects the alternative $A_{1}$ and is, essentially, indifferent with regards to $A_{3}$ and $A_{4}$ 


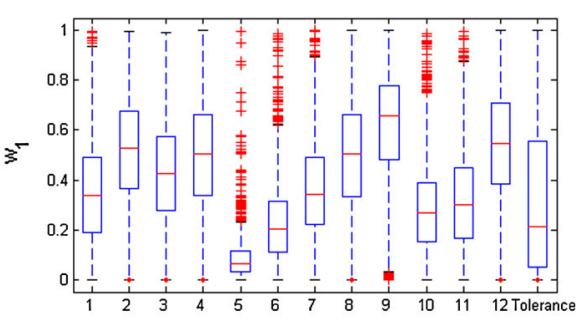

Decision Maker

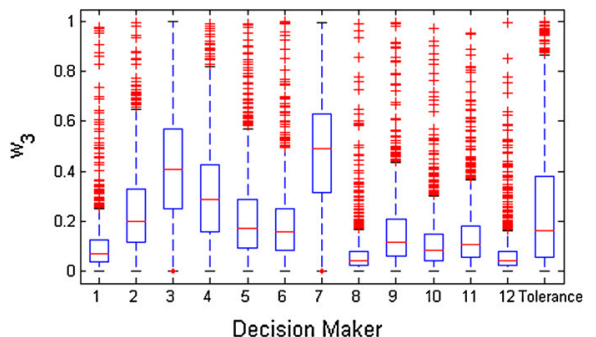

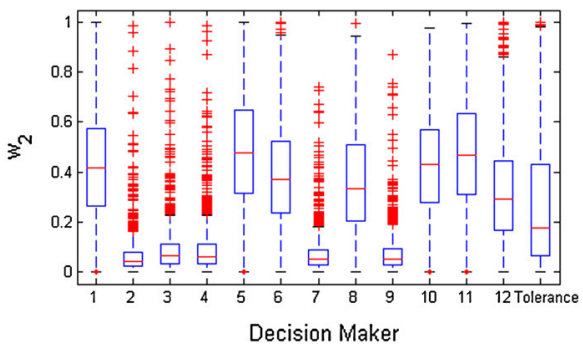

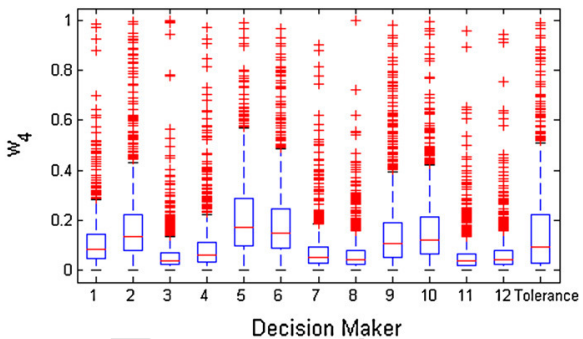

Fig. 2 Boxplot of the individual posterior distributions of decision makers' priorities and the tolerance distribution

(Tables 3, 6 and 7). The fourth group has a total weight of $8 \%$ and contains decision makers $\mathrm{D}_{8}$ and $\mathrm{D}_{12}$ who set alternatives $\mathrm{A}_{1}$ and $\mathrm{A}_{2}$ as the most and the second most preferred alternatives. All the decision makers manifested a high degree of consistency in the judgement elicitation process (Table 2) and provided well determined rankings for the alternatives.

\subsection{Tolerance distribution}

Tables 2, 3, 4, 5, 6, and 7 and Figs. 1 and 2 also show, under Tolerance, the inferences made about the groups' joint priorities using a sample drawn from the tolerance distribution (17). The algorithm described in Sect. 4.2 was used with $S=1000$ and $S^{\prime}=10000$. It can be observed that this distribution represents a compromise opinion among the various preferences given in Sect. 3.1. Tables 3, 4, and 5 show that the tolerance distribution favors the selection of alternative $\mathrm{A}_{1}$ as the most preferred and $\mathrm{A}_{4}$ as the least preferred.

The proposal reflects the existence of a majority of decision makers who show strong affinity to $A_{1}$. With the exception of $D_{5}$, all the decision makers prefer $A_{1}$ as the first or second most preferred alternative with a majority $\left(\mathrm{D}_{2}, \mathrm{D}_{3}, \mathrm{D}_{4}, \mathrm{D}_{8}, \mathrm{D}_{9}\right.$ and $\mathrm{D}_{12}$, total weight $46 \%$ ) who consider it to be the most suitable (see implied rankings of Table 4) and with strong intensity (see relative preferences $\mathrm{w}_{1} / \mathrm{w}_{\mathrm{i}} \mathrm{i}=2,3,4$ in Table 7). Alternative $\mathrm{A}_{4}$ is the least suitable, with the only exception of $\mathrm{D}_{5}$, all the decision makers tend place it third or fourth (Tables 3, 6) with middle/strong intensity for most of the decision makers (see relative preferences $w_{4} / w_{i} i=1,2,3$ in Table 7). There is no clear difference between alternatives $\mathrm{A}_{2}$ and $\mathrm{A}_{3}$. If we consider the results of Table $3, \mathrm{~A}_{3}$ is selected as the second most preferred by the tolerance distribution, reflecting that decision makers $\mathrm{D}_{2}, \mathrm{D}_{3}, \mathrm{D}_{4}$ and $\mathrm{D}_{9}$ (total weight $38 \%$ ) selected it in second place while only $\mathrm{D}_{8}$ and $\mathrm{D}_{12}$ (total weight $8 \%$ ) selected $\mathrm{A}_{2}$ as the second most preferred. However, (Table 3) decision makers $\mathrm{D}_{1}, \mathrm{D}_{5}, \mathrm{D}_{6}, \mathrm{D}_{10}$ and $\mathrm{D}_{11}$ (total weight $50 \%$ ) selected $\mathrm{A}_{2}$ as the most preferred alternative while only $\mathrm{D}_{7}$ (weight $4 \%$ ) preferred $\mathrm{A}_{3}$. This fact is reflected in the results shown in Tables 6 and 7 from which it is concluded that $A_{2}$ dominates $A_{3}$, but with a high probability of rank reversal $\left(P\left(A_{3} \succ A_{2}\right)\right.$ 


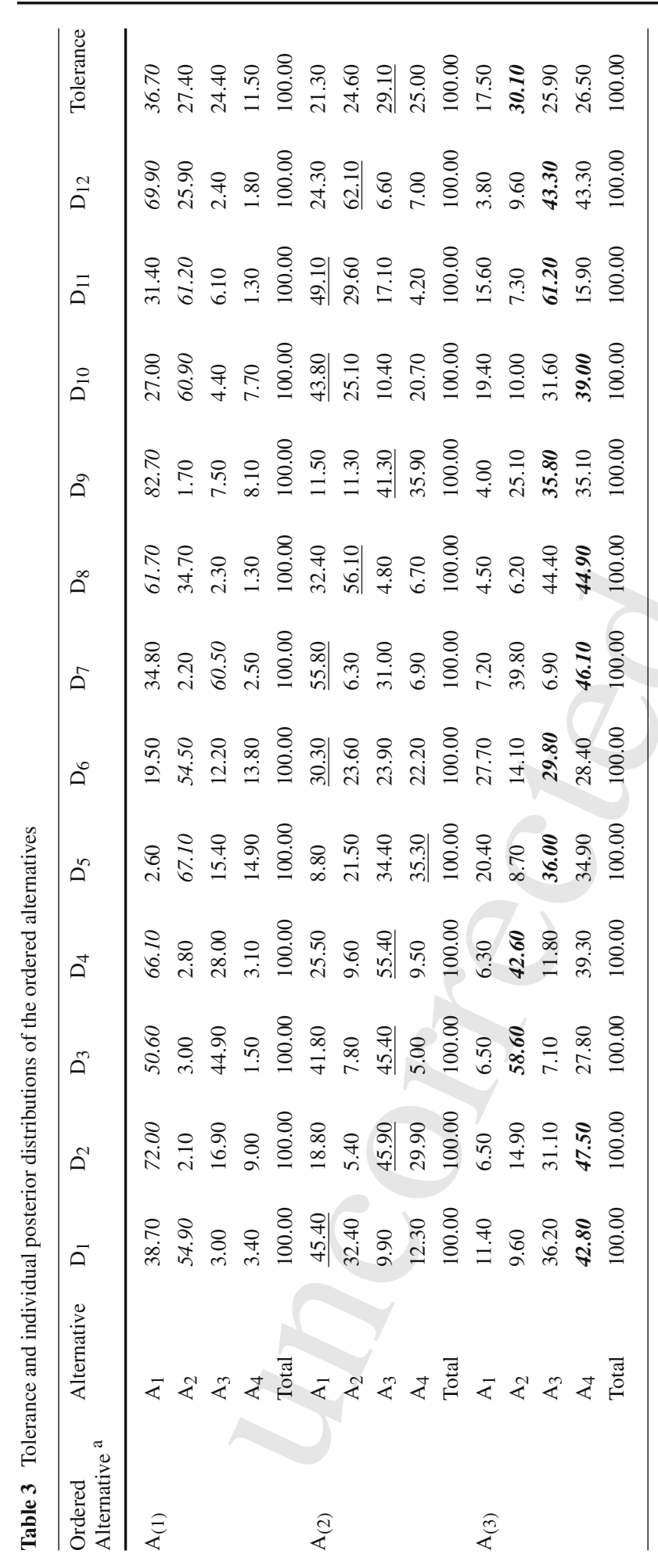

\section{算 Springer}




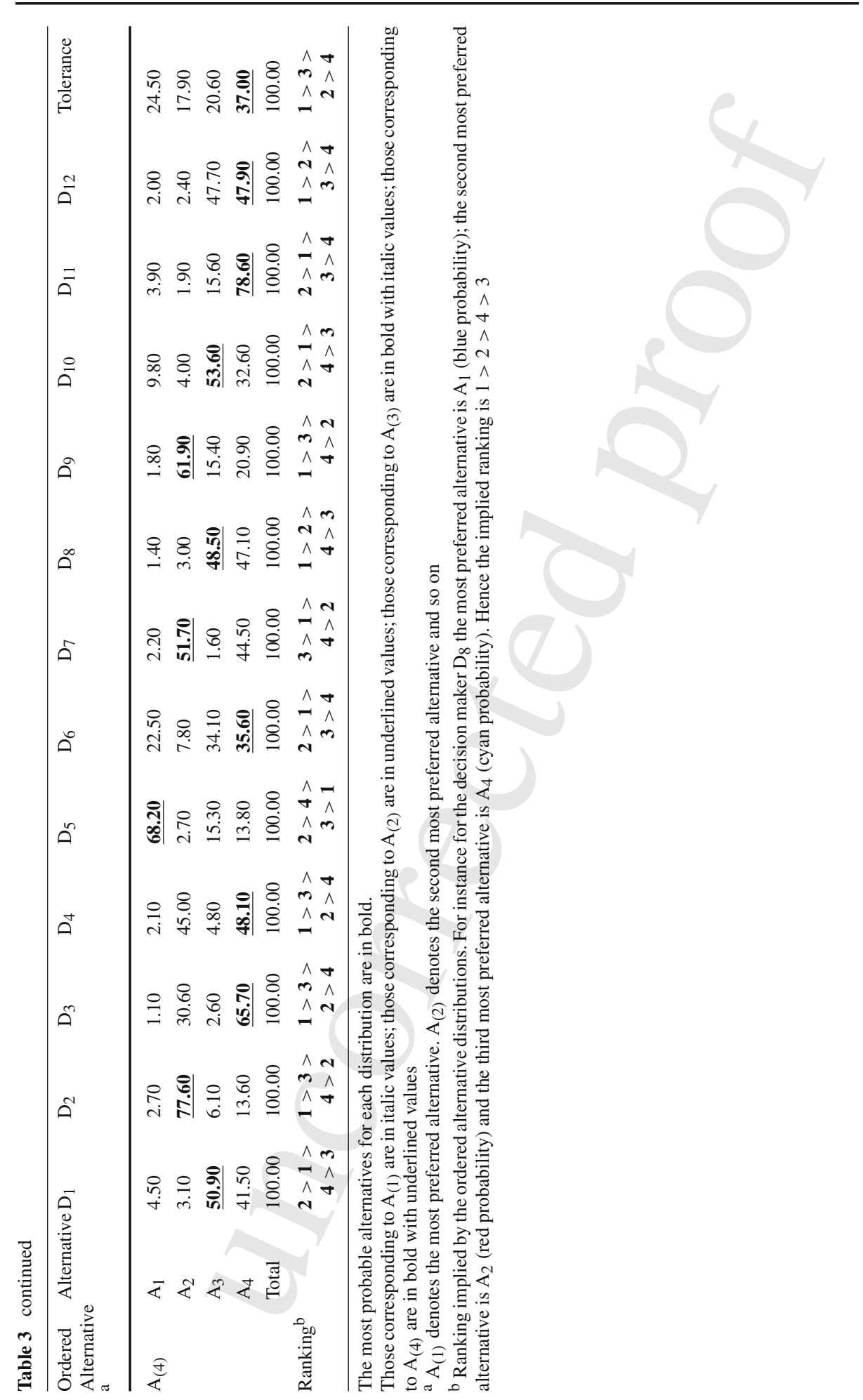




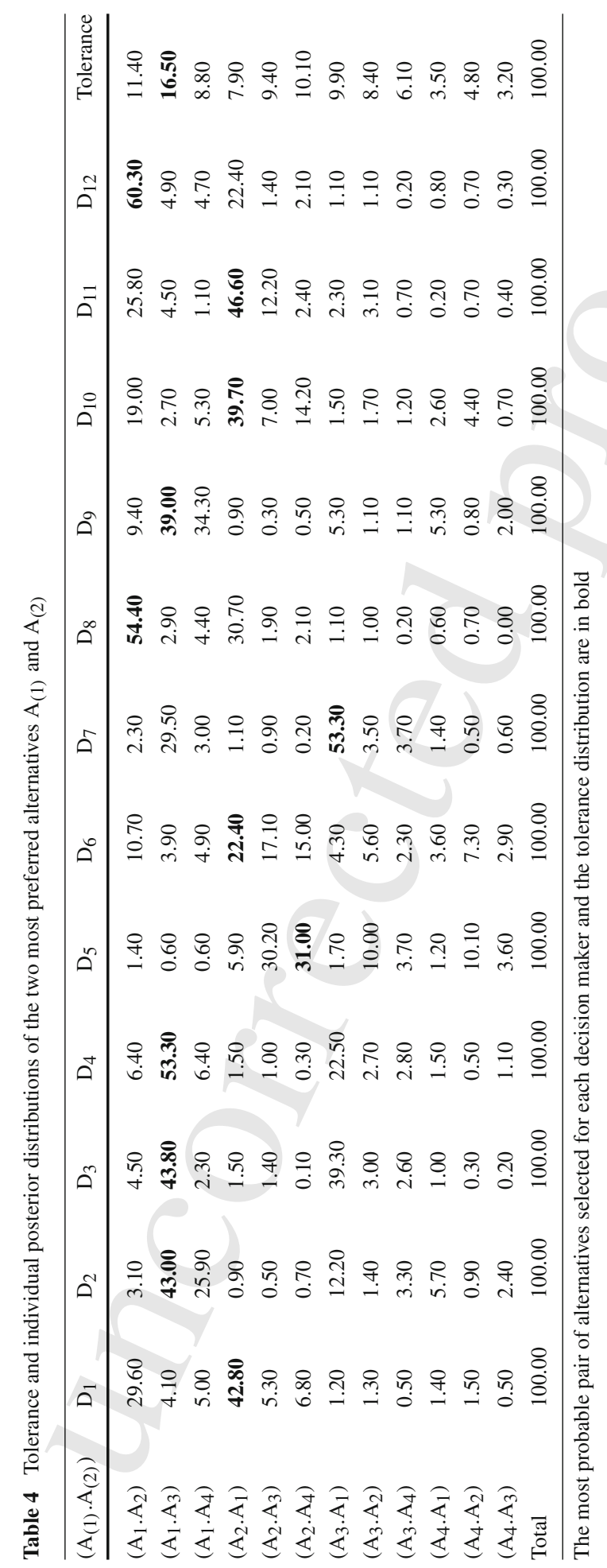

\section{望 Springer}




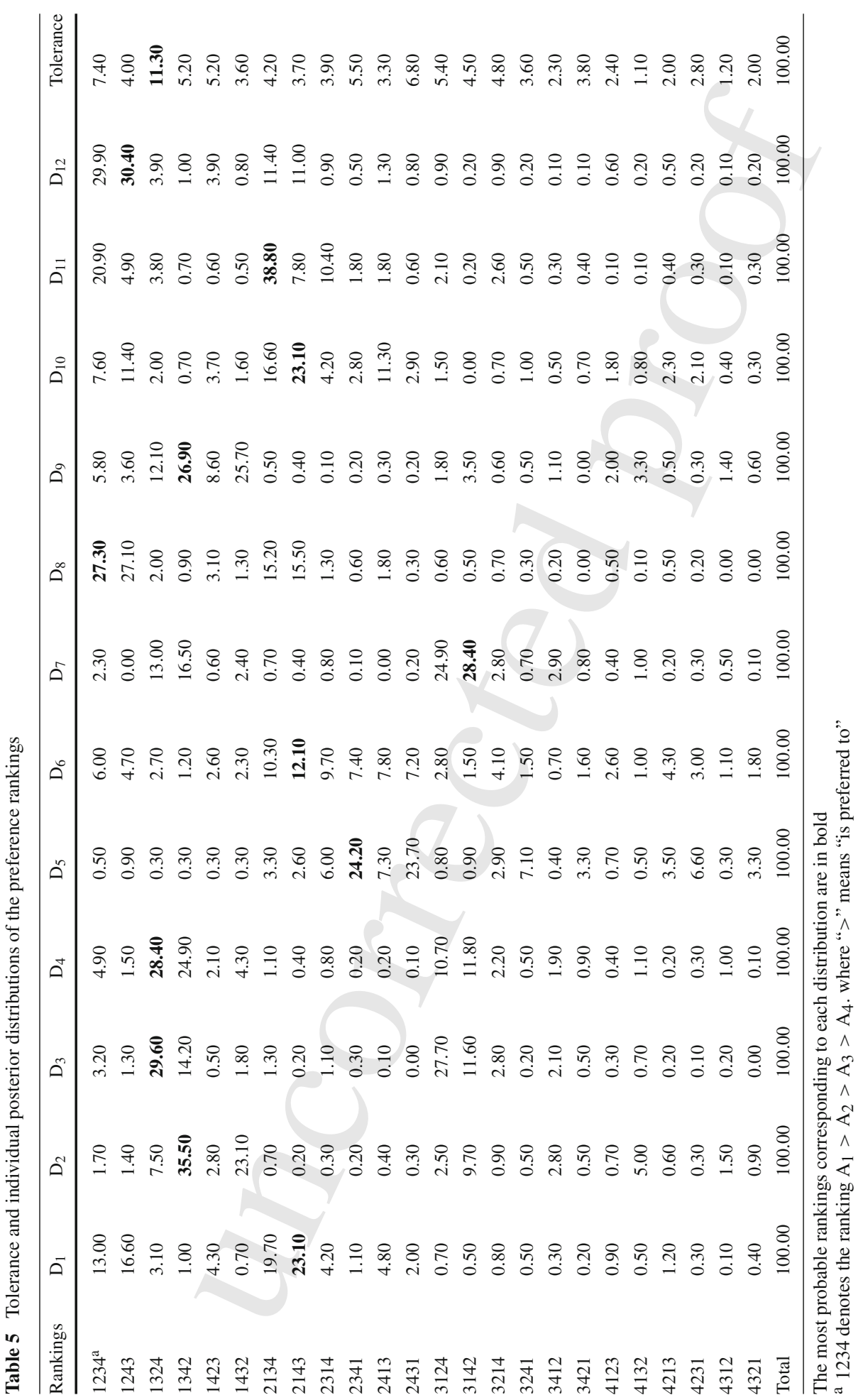




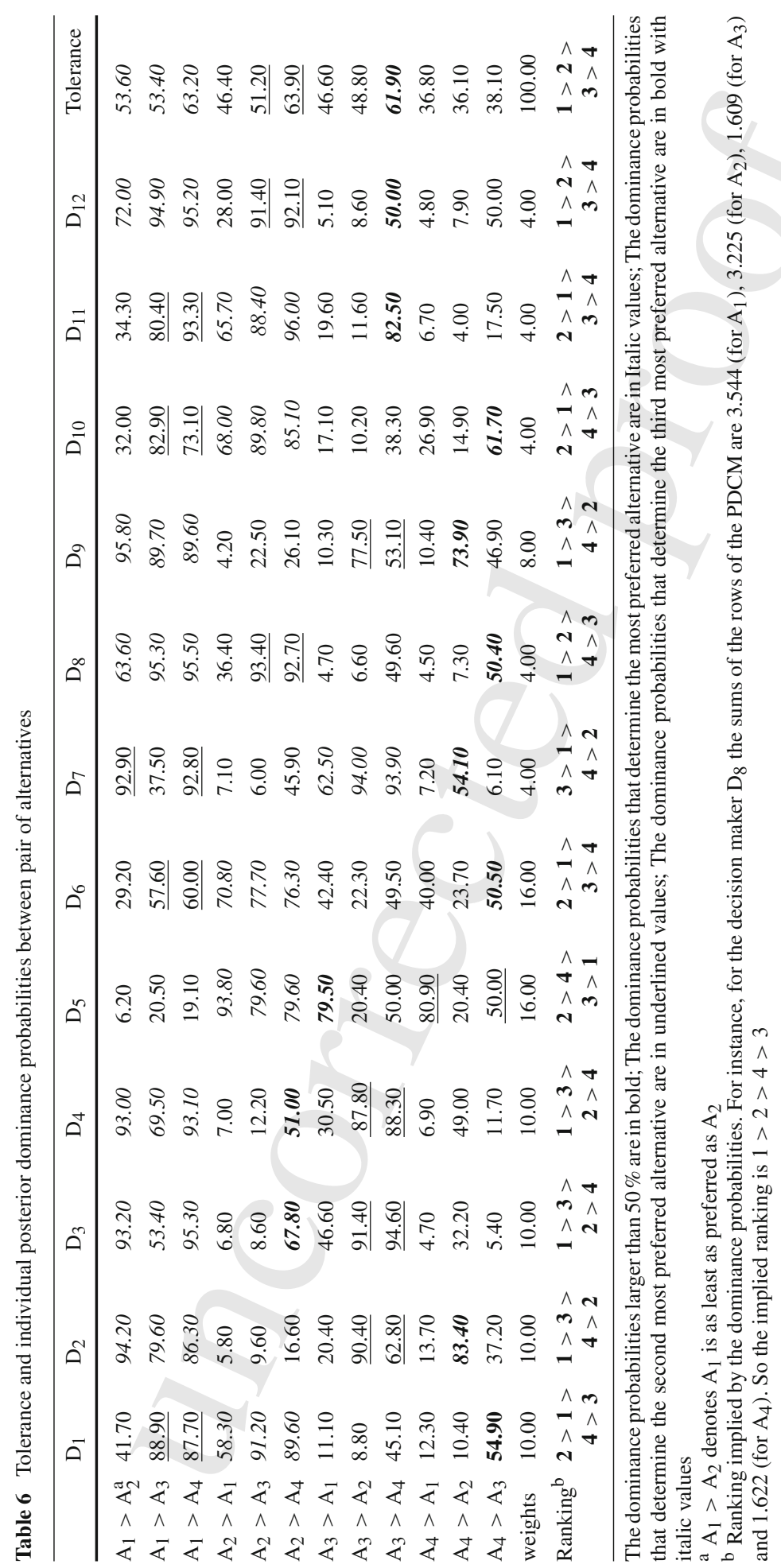

照 Springer 


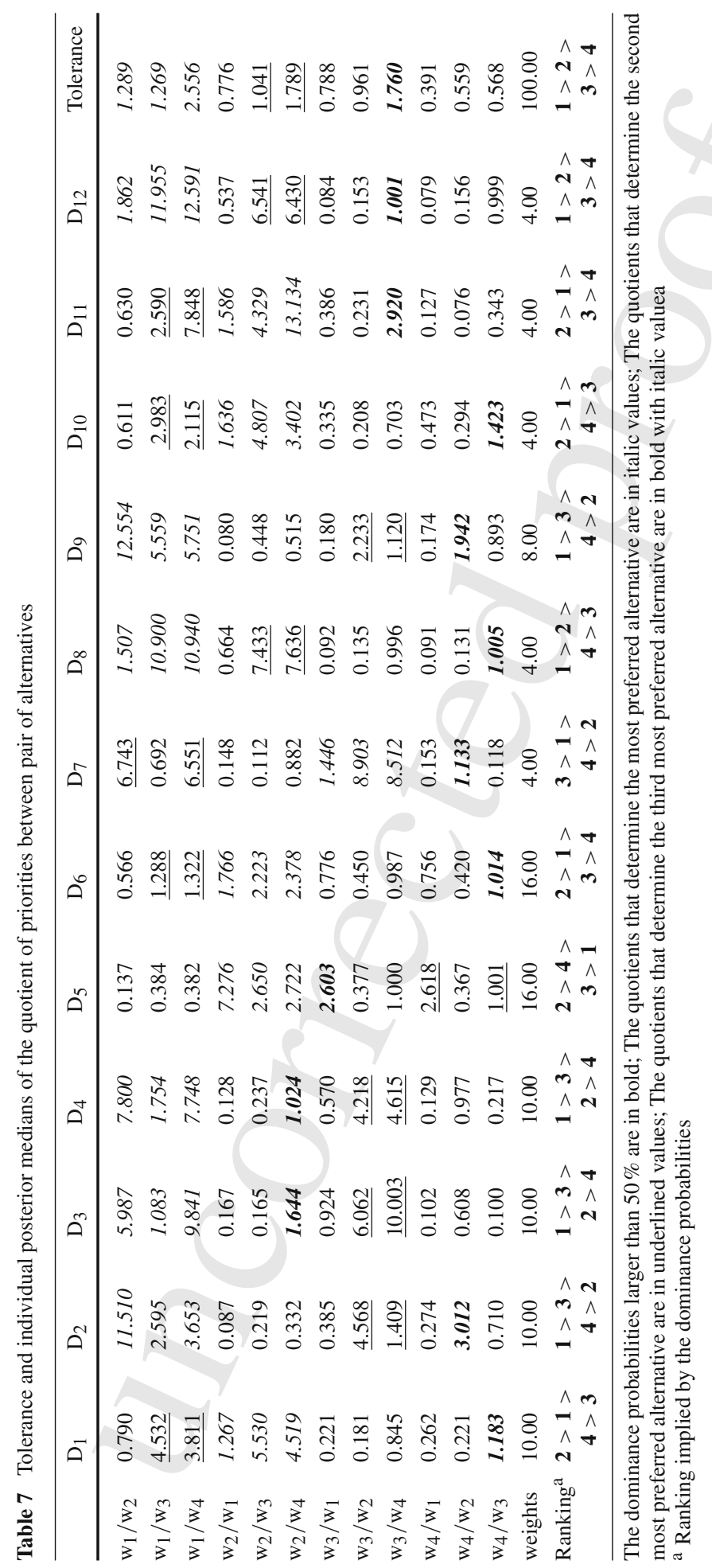


$=0.488$ with the tolerance distribution (Table 6) and a weak relative preference of $\mathrm{A}_{2}$ with respect to $\mathrm{A}_{3}\left(\frac{\mathrm{w}_{2}}{\mathrm{w}_{3}} \approx 1.041, \frac{\mathrm{w}_{3}}{\mathrm{w}_{2}} \approx 0.961\right.$, Table 7$)$.

Alternative $A_{1}$ could therefore be selected as the most suitable alternative and $A_{4}$ as the least preferred. With respect to the alternatives $A_{2}$ and $A_{3}$, there is no consensus in the group about the arrangement between them and it would be necessary to start a subsequent tolerance process that would conclude in a preference ranking accepted by the majority of the actors involved in the resolution process.

\section{Conclusions}

This paper presents a new approach to multi-actor decision making (systemic decision making - SDM), which has been applied, with a Bayesian perspective, in the specific context of AHP. In accordance with the principle of tolerance that characterises this new approach, SDM allows the holistic integration of the visions of reality associated with the actors involved in the resolution process. A tolerance distribution for the group's priorities vector has been defined. The distribution minimises a weighted average of the Kullback-Leibler distances to every posterior distribution of the individual priorities vector and provides a democratic tool which highlights the more probable priority vectors for reaching a final agrement by all the members of $\mathbf{D}$. The methodology has been illustrated by applying it to the multiplicative model usually employed with stochastic AHP, for known and unknown variances. Furthermore, an e-participatory budget allocation problem has been analysed in which several resolution proposals were made using the decision tools introduced in the paper.

As with any aggregation procedure or synthesis measure, some of the actors involved in the construction of the tolerance distribution may not be in agreement or hold opinions compatible with the final result. In these situations, it would be necessary to identify maximum compatible sets of actors and to provide (changing the initial priorities) tolerance paths between them in order to increase the representativeness of the tolerance distribution. These two issues (compatibility and tolerance paths) will be the subject of another paper (Salvador et al. 2014). The representativeness of the tolerance distribution, that is to say, the weight of the actors that are compatible with it, guarantees that the conclusions (patterns of behaviour of the alternatives) derived from it will be accepted by a representative or qualified number of actors. In order to measure this representativeness, measurements of discrepancy of the preference distribution of each decision maker (quantified by the individual posterior distributions (2)) such as that introduced in Altuzarra et al. (2010) could be used.

Even though this paper only considers a local context, the new approach can be extended to AHP hierarchies. In that case, the components of the priority vector $\mathbf{w}$ would be the global priorities of each alternative and it would not be necessary for the decision makers to use the same hierarchy to establish them. Moreover, given that the tolerance distribution is a joint multivariate distribution of the components of $\mathbf{w}$, it takes into account the existing statistical dependencies among them in order to analyse the preference ranking of the alternatives. This allows both the evaluation of the probabilities of rank reversal and the extraction of the multivariate preference patterns, and this could be very useful for establishing new tolerance paths. All these aspects reflect the flexibility and generality of the new approach with respect to other methodologies detailed in the literature (Ramanathan 1997; Stam and Silva 1997). Finally, it should be mentioned that although in this paper the AHP context has been adopted, the SDM framework provides a general and flexible methodology which allows the actors to employ different multicriteria approaches, the only requisite being that the preferences of 
each actor can be expressed by a probability distribution. All this gives the proposal a high level of realism, flexibility and generality that will become more apparent in future papers.

Acknowledgments This work was partially financed by the project "Social Cognocracy Network" (Ref. ECO2011-24181), supported by the Spanish Ministry of Science and Innovation.

\section{References}

Aguarón, J., Escobar, M. T., \& Moreno-Jiménez, J. M. (2014). Precise consistent consensus matrix. Annals of Operations Research. doi:10.1007/s10479-014-1576-8.

Aguarón, J., \& Moreno-Jiménez, J. M. (2003). The geometric consistency index. Approximated thresholds. European Journal of Operational Research, 147(1), 137-145.

Aitchison, J. (1986). The statistical analysis of compositional data. London: Chapman and Hall.

Alho, J. M., \& Kangas, J. (1997). Analyzing uncertainties in experts' opinions of forest plan performance. Forest Science, 43, 521-528.

Altuzarra, A., Gargallo, P., Moreno-Jiménez, J. M., \& Salvador, M. (2013). Influence, relevance and discordance of criteria in AHP-global Bayesian prioritization. International Journal of Information Technology \& Decision Making, 12(4), 837-861.

Altuzarra, A., Moreno-Jiménez, J. M., \& Salvador, M. (2007). A Bayesian priorization procedure for AHPgroup decision making. European Journal of Operational Research, 182, 367-382.

Altuzarra, A., Moreno-Jiménez, J. M., \& Salvador, M. (2010). Consensus building in AHP-group decision making: A Bayesian approach. Operations Research, 58(6), 1755-1773.

Bellucci, E., \& Zeleznikow, J. (2005). Trade-Off Manipulations in the Development of Negotiation Decision Support Systems. In M. Conley Tyler, E. Katsh, D. Choi (Eds.) Proceedings of the Third Annual Forum on Online Dispute Resolution. International Conflict Resolution Centre. The University of Melbourne in collaboration with the United Nations Economic and Social Commission for Asia and the Pacific. (http:// www.odr.info/unforum2004/bellucci_zeleznikow.htm).

Bryson, N. (1996). Group decision-making and the analytic hierarchy process: Exploring the consensusrelevant information content. Computers \& Operations Research, 23, 27-35.

Bryson, N., \& Joseph, A. (1999). Generating consensus priority point vectors: A logarithmic goal programming approach. Computers \& Operations Research, 26(6), 637-643.

Chen, Y. M., \& Huang, P.-N. (2007). Bi-negotiation integrated AHP in suppliers' selection. International Journal of Operations \& Production Management, 27(11), 1254-1274.

Cho, Y.-G., \& Cho, K.-T. (2008). A loss function approach to group preference aggregation in the AHP. Computers \& Operations Research, 35(3), 884-892.

Davidson, J. (1994). Stochastic limit theory. Oxford: Oxford University Press.

De Bono, E. (1970). Lateral thinking. Baltimore, MD: Penguin Books.

Dong, Y. C., Zhang, G. Q., Hong, W. Q., \& Xu, Y. F. (2010). Consensus models for AHP group decision making under row geometric mean prioritization method. Decision Support Systems, 49, 281-289.

Escobar, M. T., \& Moreno-Jiménez, J. M. (2007). Aggregation of individual preference structures. Group Decision and Negotiation, 16(4), 287-301.

Forman, E., \& Peniwati, K. (1998). Aggregating individual judgments and priorities with the Analytic Hierarchy Process. European Journal of Operational Research, 108, 165-169.

Gargallo, P., Moreno-Jiménez, J. M., \& Salvador, M. (2007). AHP-group decision making: A Bayesian approach based on mixtures for group identification. Group Decision and Negotiation, 16(6), 485-506.

Gelman, A., Carlin, J. B., Stern, H. S., \& Rubin, D. B. (2004). Bayesian data analysis. Texts in statistical science (2nd ed.). London: Chapman \& Hall/CRC.

Genest, C., \& Rivest, L. P. (1994). A statistical look at Saaty's method of estimating pairwise preferences expressed on a ratio scale. Journal of Mathematical Psychology, 38, 477-496.

Geweke, J. (1989). Bayesian inference in econometric models using Monte Carlo integration. Econometrica, 57, 1317-1340.

Hahn, D. (2003). Decision making with uncertain judgements: A stochastic formulation of the analytic hierarchy process. Decision Sciences, 34(3), 443-446.

Hahn, D. (2006). Link function selection in stochastic multicriteria decision making models. European Journal of Operational Research, 172, 86-100.

Hämäläinen, R. P., \& Pöyhönen, M. (1996). On-line group decision support by preference programming in traffic planning. Group Decision and Negotiation, 5(4), 485-500. 
Hämäläinen, R. P. (2003). Decisionarium-aiding decisions, negotiating and collecting opinions on the web. Journal Multi-Criteria Decision Analysis, 12(2-3), 101-110.

Hosseinian, S., Navidi, H., \& Hajfathaliha, A. (2012). A new linear programming method for weights generation and group decision making in the analytic hierarchy process. Group Decision and Negotiation, 21(3), 233-254.

Huang, Y. S., Liao, J. T., \& Lin, Z. L. (2009). A study on aggregation of group decisions. Systems Research and Behavioral Science, 26(4), 445-454.

Laininen, P., \& Hämäläinen, R. P. (2003). Analyzing AHP-matrices by regression. European Journal of Operational Research, 148, 514-524.

Lipovetsky, S. (2009). Linear regression with special coefficient features attained via parameterization in exponential, logistic, and multinomial-logit forms. Mathematical and Computer Modelling, 49(7-8), 14271435 .

Mikhailov, L. (2004). Group prioritization in the AHP by fuzzy preference programming method. Computers \& Operations Research, 31(2), 293-301.

Moreno-Jiménez, J. M. (2003a). Los Métodos Estadísticos en el Nuevo Método Científico. In J. M. Casas \& A. Pulido (Eds.), Información económica y técnicas de análisis en el siglo XXI (pp. 331-348). Instituto Nacional de Estadística (INE).

Moreno-Jiménez J.M. (2003b). Las Nuevas Tecnologías y la Representación Democrática del Inmigrante. En ARENERE, J.: IV Jornadas Jurídicas de Albarracín (22 pp). Consejo General del Poder Judicial. TSJA, Memoria Judicial Anual de Aragón del año 2003, p. 66.

Moreno-Jiménez, J. M. (2006). E-cognocracia: Nueva sociedad, nueva democracia. Estudios de Economía Aplicada, 24(1-2), 559-581.

Moreno-Jiménez, J. M., Aguarón, J., \& Escobar, M. T. (2001). Metodología científica en valoración y selección ambiental. Pesquisa Operacional, 21, 3-18.

Moreno-Jiménez, J. M., Aguarón, J., \& Escobar, M. T. (2008). The core of consistency in AHP-group decision making. Group Decision \& Negotiation, 17, 249-265.

Moreno-Jiménez, J. M., Aguarón, J., Raluy, A., \& Turón, A. (2005). A spreadsheet module for consistent AHP-consensus building. Group Decision \& Negotiation, 14(2), 89-108.

Moreno-Jiménez, J. M., \& Polasek, W. (2003). E-democracy and knowledge. A multicriteria framework for the new democratic era. Journal Multi-criteria Decision Analysis, 12, 163-176.

Moreno-Jiménez, J. M., \& Vargas, L. G. (1993). A probabilistic study of preference structures in the analytic hierarchy process with Interval Judgments. Mathematical and Computer Modelling, 17(4-5), 73-81.

Peniwati, K. (2007). Criteria for evaluating group decision-making methods. Mathematical and Computer Modelling, 46(7-8), 935-947.

Ramanathan, R. (1997). Stochastic decision making using multiplicative AHP. European Journal of Operational Research, 97, 543-549.

Ramanathan, R., \& Ganesh, L. S. (1994). Group preference aggregation methods employed in AHP: An evaluation and intrinsic process for deriving members' weightages. European Journal of Operational Research, 79, 249-265.

Ramsay, J. O. (1977). Maximum likelihood estimation in multidimensional scaling. Psychometrika, 42, 241266.

Roy, B. (1985). Methodologie Multicritère d'Aide à la Décision. Gestion Economica.

Rubin, D. (1987). A noniterative sampling/importance resampling alternative to the data augmentation algorithm for creating a few imputations when fractions of missing information are modest: the SIR algorithm. Journal of the American Statistical Association, 82, 543-546.

Saaty, T. L. (1972). An eigenvalue allocation model in contingency planning. University of Pennsylvania, 19, 72.

Saaty, T. L. (1980). Multicriteria decision making: The analytic hierarchy process. New York: Mc Graw-Hill. (2nd impression 1990, RSW Pub. Pittsburgh, PA).

Saaty, T. L., \& Peniwati, K. (2008). Group decision making: Drawing out and reconciling differences. Pittsburgh, PA: RWS Publications.

Salvador, M., Gargallo, P., \& Moreno-Jiménez, J.M. (2014). A Bayesian approach to maximizing inner compatibility in AHP-Systemic Decision Making. Group Decision \& Negotiation. (Forthcoming).

Stam, A., \& Silva, A. P. D. (1997). Stochastic judgements in the AHP: The measurement of rank reversal probabilities. Decision Science, 28(3), 655-688.

Van den Honert, R. C., \& Lootsma, F. A. (2000). Assessing the quality of negotiated proposals using the REMBRANDT system. European Journal of Operational Research, 120(1), 162-173.

Van den Honert, R. C. (1998). Stochastic group preference modelling in the multiplicative AHP: A model of group consensus. European Journal of Operational Research, 110(1), 99-11. 